\title{
Reflexiones constitucionales a propósito del COVID-19'
}

Constitutional reflections regarding COVID-19

\author{
Diego Valadés ${ }^{2}$ \\ Universidad Nacional Autónoma de México - México
}

Revista Derechos en Acción ISSN 2525-1678/ e-ISSN 2525-1686

Año 5/Nº 15, Otoño 2020 (21 marzo a 21 junio), $321-329$

DOl: https://doi.org/10.24215/25251678e401

La pandemia del COVID-19 también ha afectado la salud de las instituciones políticas y de la economía planetarias.

Cuando la emergencia haya quedado atrás, además del balance que se lleve a cabo, lo natural será que en los distintos países se recapitule acerca de lo ocurrido y de los ajustes que deberán emprender para afinar, corregir o fortalecer su aparato institucional.

Esta crisis ha hecho que por primera vez en la historia los habitantes de buena parte del planeta se hayan encontrado recluidos en sus casas habitación de manera simultánea, poniéndose a resguardo de la misma amenaza. Un sentimiento de temor cruzó por todos los hogares del mundo sin distinguir niveles socioeconómicos. Esto generó una conciencia de empatía global nunca antes registrada.

\footnotetext{
1 A Héctor Fix-Fierro, amigo muy querido y jurista muy admirado.

2 Investigador emérito del Instituto de Investigaciones Jurídicas de la Universidad Nacional Autónoma de México y del Sistema Nacional de Investigadores. Doctor en Derecho, Universidad Complutense de Madrid. Es miembro de El Colegio Nacional, de El Colegio de Sinaloa, de la Academia Mexicana de la Lengua y de la Academia Mexicana de Ciencias, Presidente del Instituto Iberoamericano de Derecho Constitucional. Doctor honoris causa de la Universidad de Buenos Aires. (ORCID 0000-0002-5551-4266).
} 
El seguimiento noticioso sobre la diseminación del virus ha estado acompañado por el relativo a las diferentes medidas sanitarias, jurídicas, económicas y políticas que se van dando en los países afectados.

Un aspecto llamativo fue la drasticidad de las medidas adoptas en China, de las que Wuhan se convirtió en el punto emblemático. La pregunta acerca de si sería posible imponer semejantes restricciones en sociedades democráticas fue respondida en sentido afirmativo, como atestiguaron las calles y plazas de España e Italia, por ejemplo. Aunque los tiempos de reacción no fueron semejantes, la magnitud del parón sí lo fue. No tardó en darse otro hecho inusitado: el cierre de fronteras entre algunos países de la Unión Europea.

Llegada la pandemia a Estados Unidos se pusieron en marcha cuatro tipos de medidas: las internas de cada estado, las compartidas entre dos o más de ellos, las acordadas entre el Estado federal y uno o varios estados, y las dictadas para todo el país. Se adicionaron las disposiciones acordadas por las autoridades de nivel municipal. La multiplicidad de acciones exhibió los problemas de coordinación que ocasionan los errores de diseño en un Estado compuesto. Los Estados unitarios operaron sus decisiones de una manera más homogénea. Queda planteada la conveniencia de un análisis particular luego que la crisis sea remontada, para apreciar los resultados, conforme a las mediciones especializadas en salud, en los sistemas descentralizados, federales o regionales, y en los unitarios.

En el caso de México el COVID-19 ha sometido al Estado a un estrés de enormes proporciones. A la naturaleza del mal se asociaron múltiples factores que pusieron a la sociedad y a las autoridades en una tensión desusada. Es temprano para recapitular sobre los aciertos y los errores de las medidas aplicadas; sólo la perspectiva del tiempo permitirá una evaluación despojada de subjetividad. Los resultados serán valorados de manera empírica en términos de salud y en cuanto al impacto en el empleo, la pobreza y el producto nacional. Además, se podrá medir la eficacia de las instituciones, la confianza que 
inspiraron y el aprecio social por los dirigentes y las políticas que adoptaron.

En México pueden distinguirse dos planos: el de la política coyuntural, donde se acentuó la polarización que ya venía de tiempo atrás, y el de la capacidad de respuesta institucional, que se vio condicionada por el verticalismo gubernamental combinado con la debilidad de los sistemas representativo y federal. El aspecto institucional está llamado a ocupar la atención post crisis y exigirá en el futuro cercano soluciones constructivas.

Hubo lugares, México incluido, donde un primer impulso negacionista pretendió minimizar la pandemia aduciendo que otras enfermedades causan un número más elevado de fallecimientos y que varias pandemias previas fueron más letales de lo que apunta ser la actual. Es cierto que esta no ha sido la más letal de la historia, ni siquiera de la contemporánea (recuérdese, por ejemplo, la mal llamada gripe española), en cambio sí ha sido la que ha ocasionado la mayor conmoción. Esto denota que emergió una sociedad planetaria que, además de compartir de manera directa y simultánea una experiencia adversa, plantea expectativas comunes. Para satisfacerlas habrá que contar con instituciones más responsables y mejor construidas para dar respuestas certeras y oportunas, y disponer de recursos científicos, económicos, financieros y tecnológicos capaces de satisfacer demandas imprevistas de magnitud excepcional.

Todo lo anterior exige un Estado constitucional operativo y funcional. En la medida en que todo cuanto está implicado en la solución de una emergencia exige capacidad de coordinación y ejecución, sólo el Estado democrático puede dar respuestas razonables, pues es el único ente organizado y con atributos coercitivos legítimos que existe.

Se necesita un Estado apto para responder a las exigencias crecientes de bienestar y seguridad que, a la vez, promueva los derechos humanos y satisfaga las aspiraciones democráticas de las sociedades. El COVID-19 es sólo uno de los fenómenos que 
someterá a prueba a la humanidad. La falta de compromisos serios por parte de las grandes economías en cuanto a reducir los riesgos crecientes del cambio climático, augura una etapa de percances como inundaciones y sequías, ciclones e incendios, que ocasionarán hambre, desempleo, enfermedad, muerte, desplazamientos y posibles reacciones sociales de exacerbación.

Todo eso es remediable si se diseñan y adoptan a tiempo instituciones democráticas que limiten la discrecionalidad de los gobernantes. Como hemos visto en la experiencia de COVID-19, en sistemas de fuerte concentración del poder las soluciones se volvieron personales e inapelables. En los sistemas democráticos el poder está desconcentrado, por lo que se multiplican los sensores sociales y políticos. Esto los hace más receptivos y sensibles y por ende tienen mejores posibilidades de dar respuestas acertadas y oportunas.

En México, como en casi todos los países, la opinión acerca del manejo de la crisis sanitaria se dividió. Esto no es relevante. Lo que sí cuenta es que los órganos de representación política, federales y locales, tuvieron una presencia menor. No hubo deliberación acerca de las medidas sanitarias y por ende acabaron siendo decisiones dictadas de manera vertical, no secundadas por las fuerzas políticas, a diferencia de lo sucedido en los sistemas presidenciales reformados y en los sistemas parlamentarios. El Congreso de la Unión tampoco intervino en la aprobación de las medidas económicas para preservar las fuentes de trabajo. En un momento de máxima visibilidad de la actuación del poder, el sistema representativo mexicano se difuminó.

Otro factor que se hizo ostensible fue la insubstancialidad prevaleciente de los altos cargos y la ausencia de un servicio profesional administrativo de calidad. Predomina el modelo de funcionarios silentes, a veces incluso transparentes, que simbolizan la paradoja de ser servidores públicos refractarios al público. En los sistemas constitucionales democráticos los integrantes de los gobiernos son figuras con opinión y posición, expuestas al contacto con los medios y con los representantes políticos de la nación, obligadas a rendir cuenta permanente de 
su actividad. En un sistema democrático las razones del poder deben ser explícitas siempre, y la idoneidad de los funcionarios principales debe ser valorada por los gobernados y por sus representantes, no sólo por quien los designa.

En cuanto al servicio civil, su carencia es típica de los sistemas patrimonialistas donde las elecciones sirven para escoger conquistadores. Los vencedores se asumen como usufructuarios del aparato administrativo y lo reparten conforme a afectos, afinidades, intereses o pactos. Las administraciones colonizadas exhiben su disfuncionalidad al verse en medio de presiones excepcionales como la emergencia sanitaria.

Durante esta difícil etapa se ha evidenciado la ausencia de la oposición. Hecha la salvedad de algunas figuras políticas, los partidos mostraron su irrelevancia. Esto también es parte del déficit institucional pues los partidos son la base de toda democracia representativa. Su debilidad no se debe a los resultados electorales ni a las capacidades de sus dirigentes sino al diseño institucional del sistema. En México las minorías políticas carecen de derechos. El sistema electoral es pulcro y eficaz, pero no basta por sí solo para asegurar la democracia institucional. Mientras que en una democracia bien construida la mayoría gobierna y la minoría controla, la Constitución mexicana sigue sin incorporar controles políticos eficientes que permiten a las minorías cumplir con sus funciones.

La crisis sanitaria ha dado oportunidad para que los ciudadanos del mundo se asomen a las realidades ajenas y las conviertan en propias. En tanto que gran parte de la población planetaria ha tenido que recluirse en sus espacios domésticos, un porcentaje importante ha dispuesto de tiempo para enterarse de los sucesos en otras latitudes. Al cobrar conciencia de los diferentes sistemas y estilos de gobierno ha aprendido, o al menos intuido, que sin un Estado potente sus derechos están en riesgo.

El regreso a la normalidad no será manso ni rutinario. La reconstrucción de las economías seguirá demandando una intervención decisiva del Estado. El gran desafío general consistirá 
en que el Leviatán de nuestro tiempo esté basado en un poder cuyo buen diseño constitucional lo haga eficaz y controlable. De la posibilidad de construir controles políticos democráticos satisfactorios dependerá que el Estado cuente con instrumentos para impulsar el desarrollo, garantizar la seguridad y promover el bienestar, sin correr el peligro de deslizarse por la pendiente de la corrupción, la arbitrariedad y el paternalismo.

Otro reto que deberá afrontar el Estado constitucional del siglo XXI consiste en acelerar la construcción de los instrumentos administrativos, jurídicos, políticos y técnicos aptos para conjurar una nueva contingencia mundial, sanitaria o ambiental. La Organización Mundial de la Salud funciona de manera adecuada, pero el programa mundial del ambiente mantiene una dimensión menor y ha tropezado con la parsimonia de las economías mayores. Es indispensable aplicar todos los recursos de la diplomacia y de la política para consolidar ese organismo de ya muy larga gestación.

De la misma manera habrá que revisar los instrumentos mundiales y regionales de derechos humanos a efecto de incorporar nuevos conceptos. Uno de ellos, crucial para la democracia internacional y de las naciones, es el laicismo. La contingencia sanitaria sufrida ha reavivado las supersticiones y los fundamentalismos en perjuicio del Estado laico, y la laicidad del Estado es un presupuesto de las libertades democráticas, de la igualdad y del pluralismo.

La rotundidad de las medidas económicas aplicadas por numerosos Estados convierte una vez más a los aparatos de poder político en los rectores de la economía. Las decisiones de corte keynesiano han demostrado su potencial siempre que han sido puestas en práctica, pero J. M. Keynes también recomendó fortalecer el instrumental democrático. Para vigorizar la democracia los sistemas parlamentarios deberán resolver problemas como el de la investidura del gobierno, y los sistemas presidenciales el de la concentración personal del poder y la irresponsabilidad política de los gobiernos. 
El sistema presidencial tiene sus puntos de mayor fortaleza en la periodicidad inalterable del mandato y en la certeza de la investidura, que evita situaciones como las padecidas en Bélgica (2010-2011, 2018-2019), España (2015-2016, 2019-2020) e Israel (2019-2020), también frecuentes en Italia y en otros países. La prolongación de gobiernos en funciones es soportada gracias a sistemas robustos de servicio civil. Aun así incomoda a la sociedad, expuesta a frecuentes convocatorias electorales y a la consiguiente crispación política que las acompaña. La investidura segura y la continuidad previsible del gobierno son las mejores soluciones que aporta el sistema presidencial y hacia donde podrían encaminarse algunos sistemas parlamentarios. La censura constructiva, de origen alemán, es un paso en esa dirección.

En un sentido inverso, los sistemas presidenciales tienden a parlamentarizarse mediante la inclusión constitucional de los gabinetes, donde sus integrantes discuten y aprueban los planes y las acciones de gobierno. Sus miembros están sujetos a la confianza del Congreso y acuden a las sesiones periódicas y sistemáticas de control. La regularidad electoral y la permanencia del jefe de Gobierno ayudan a evitar la inquietud y la animosidad generadas por comicios recurrentes, como sucede en los sistemas parlamentarios. Es previsible que los estados constitucionales tiendan hacia la flexibilidad que ofrece la hibridación de los sistemas básicos. La plasticidad de los diseños constitucionales contemporáneos propicia combinaciones creativas. Cuando los sistemas mixtos están bien equilibrados potencian las ventajas y atenúan los defectos de los modelos clásicos.

En México será necesario retomar el debate sobre la renovación institucional en las esferas federal y local. La carencia de controles políticos democráticos por parte de los congresos perpetúa la incompetencia de los gobernantes y el ejercicio irresponsable del poder; los caciques son una expresión de arbitrariedad y corrupción; la falta de espacios institucionales para 
la deliberación, como podría ser un Consejo Social, mantiene la insularidad de las áreas económicas, sociales y profesionales del país, en perjuicio de posibles entendimientos y acuerdos que dinamicen nuestra vida científica, cultural y económica; la privación de instrumentos de acceso a la justicia y de un servicio civil de carrera muy profesional y riguroso en todos los niveles de gobierno, son una coartada para el patrimonialismo y la corrupción; la marginación de los representantes de la nación en la definición y evaluación de las políticas públicas, y la limitación de las minorías parlamentarias, merman el papel del sistema representativo y su credibilidad, y la concentración del poder presidencial es un arcaísmo que lastra al conjunto del Estado.

Además de reconfigurar el poder para racionalizar su ejercicio y defender la democracia, y de innovar la gobernanza internacional para la seguridad ambiental al planeta, es previsible un nuevo esquema de organización social. Los sindicatos se han significado por su declive paulatino; los sectores sociales favorecidos por políticas de renta básica carecen de organización y cohesión, y los organismos no gubernamentales avocados a la promoción y defensa de los derechos humanos actúan en campos segmentados y sin coordinación ente sí. La dispersión ha sorprendido a los trabajadores, asalariados y no asalariados, en un momento de máxima vulnerabilidad. Es probable que la ola de desempleo y sacrificios salariales auspicie el resurgimiento del concepto de clase y genere la reorganización del proletariado, con perspectiva global. Su mejor forma de lucha será a través de la democracia electoral y parlamentaria, como previó Ferdinand Lassalle desde el siglo XIX.

En adición a las profundas revisiones conceptuales y institucionales, el COVID-19 ha dado un ejemplo a gran escala de cómo las condiciones de emergencia hacen que las sociedades privilegien la vida sobre las libertades. Estas situaciones excepcionales pueden menudear (calamidades ambientales, ciclones, epidemias, erupciones volcánicas, incendios, inundaciones, terremotos, etc.) y hay casos en los que se pueden hacer 
crónicas, como durante la violencia delictiva. Para semejantes circunstancias debe contarse con instrumentos institucionales que además de facilitar las respuestas coyunturales adecuadas, garanticen la continuidad democrática.

La experiencia en curso conducirá a pactos sociales y políticos de los que resultará una nueva racionalidad del poder en sus esferas nacional e internacional. Estas reflexiones sobre los efectos potenciales del COVID-19 son preliminares. Al concluir la etapa crítica habrá que integrar una agenda para examinar la dimensión, organización y función del Estado constitucional. Será parte de un debate democrático para el que tenemos que estar preparados. En México entramos al vendaval en condiciones institucionales deficitarias y debemos aprender la lección. 